\title{
Persistent air leaks: a review with an emphasis on bronchoscopic management
}

\author{
Donald R. Lazarus ${ }^{1}$, Roberto F. Casal ${ }^{2}$ \\ ${ }^{1}$ Department of Pulmonary, Critical Care, and Sleep Section, Michael E. DeBakey VA Medical Center, Baylor College of Medicine, Houston, TX, \\ USA; ${ }^{2}$ Department of Pulmonary Medicine, The University of Texas M. D. Anderson Cancer Center, Houston, TX, USA \\ Contributions: (I) Conception and design: All authors; (II) Administrative support: All authors; (III) Provision of study materials or patients: All \\ authors; (IV) Collection and assembly of data: All authors; (V) Data analysis and interpretation: All authors; (VI) Manuscript writing: All authors; (VII) \\ Final approval of manuscript: All authors. \\ Correspondence to: Roberto F. Casal, MD. Associate Professor of Medicine, Interventional Pulmonology, Department of Pulmonary Medicine, The \\ University of Texas M.D. Anderson Cancer Center, 1400 Pressler Street, Unit 1462, Houston, TX, USA. Email: rfcasal@mdanderson.org.
}

\begin{abstract}
Persistent air leak (PAL) is a cause of significant morbidity in patients who have undergone lung surgery and those with significant parenchymal lung disease suffering from a pneumothorax. Its management can be complex and challenging. Although conservative treatment with chest drain and observation is usually effective, other invasive techniques are needed when conservative treatment fails. Surgical management and medical pleurodesis have long been the usual treatments for PAL. More recently numerous bronchoscopic procedures have been introduced to treat PAL in those patients who are poor candidates for surgery or who decline surgery. These techniques include bronchoscopic use of sealants, sclerosants, and various types of implanted devices. Recently, removable one-way valves have been developed that are able to be placed bronchoscopically in the affected airways, ameliorating air-leaks in patients who are not candidates for surgery. Future comparative trials are needed to refine our understanding of the indications, effectiveness, and complications of bronchoscopic techniques for treating PAL. The following article will review the basic principles of management of PAL particularly focusing on bronchoscopic techniques.
\end{abstract}

Keywords: Persistent air leak (PAL); bronchopleural fistula (BPF); alveolar-pleural fistula; intrabronchial valves (IBVs); pleurodesis

Submitted Sep 16, 2017. Accepted for publication Oct 17, 2017.

doi: $10.21037 /$ jtd.2017.10.122

View this article at: http://dx.doi.org/10.21037/jtd.2017.10.122

\section{Introduction}

Pneumothorax is defined as the presence of air in the pleural space between the visceral and parietal pleura (1). Air is able to enter the pleural space due to a connection between alveolar or bronchial spaces and the pleura, due to communication between the atmosphere and the pleural space, or due to gas forming organisms present in the pleural space (1). Pneumothorax caused by an abnormal connection between the bronchial or alveolar spaces and the pleura is sometimes associated with an air leak. An air leak is defined as the flow of air into the pleural space, generally through a fistulous tract either in the periphery of the lung (alveolar-pleural fistula) or in the more central airways (bronchopleural fistula). The former is the more prevalent entity and it is the one we will focus on in this manuscript. Although most air leaks resolve spontaneously with conservative management (2), some leaks are prolonged and contribute to significant morbidity $(3,4)$. Such persistent leaks often require additional treatment beyond chest tube drainage and time.

\section{Definition and etiology of persistent air leak (PAL)}

A PAL is arbitrarily defined as an air leak that lasts longer than 5-7 days $(2,4-6)$, although some authors suggest 
that an air leak in the setting of secondary spontaneous pneumothorax should be called persistent after more than 48 hours $(7,8)$. The typically utilized 5 -day cut off to define PAL is based on the expected length of stay after lobectomy. Most common causes of PAL include thoracic surgery, chest trauma, secondary spontaneous pneumothorax (related to underlying lung disease), cavitary pulmonary infections (especially tuberculosis), lung biopsies, and as a complication of mechanical ventilation.

\section{Incidence and clinical relevance}

The overall incidence of PAL is unknown. The most commonly reported cause of PAL is lung surgery (9). In patients undergoing lung volume reduction surgery (LVRS), the incidence of PAL is high-46\% in the National Emphysema Treatment Trial (3). The incidence of PAL after lobectomy is lower, ranging from $5.6 \%$ to $26 \%$ in various reports $(4,10-13)$. While the incidence of PAL after secondary spontaneous pneumothorax is not known, it is certainly much lower than in the setting of postoperative air-leak (9). The incidence of PAL in patients on mechanical ventilation has not been well described. Pierson et al. reported 39 cases of PAL out of 1,700 patients (2.2\%) undergoing mechanical ventilation over 4 years at a single trauma center. Average tidal volume in this cohort was $14.6 \mathrm{~mL} / \mathrm{kg}$, which is not consistent with modern practice and suggests that the rate of PAL in a similar cohort in the current decade may be even lower (14).

Mortality in patients with post-surgical PAL is not clearly increased, although morbidity is significantly affected in these patients. In the 552 patients participating in the National Emphysema Treatment Trial who received LVRS mortality was not significantly different whether or not a PAL was present (3). DeCamp and colleagues compared 54 LVRS patients with PAL with propensity-matched controls who did not have PAL. The patients with PAL had a higher incidence of overall postoperative complications than the propensity-matched controls (57\% vs. $30 \%$, $\mathrm{P}=0.004)$. The most commonly reported complications were pneumonia and readmission to the intensive care unit. LVRS patients with PAL also had increased length of hospital stay when compared to matched controls (11.8 vs. 7.6 days, $\mathrm{P}=0.0005$ ) (4). This result is consistent with data published by Liberman and colleagues who reported their experience with PAL after major pulmonary resection. In their cohort, mortality remained low in patients with PAL $(1.2 \%)$. Post-operative pneumonia was more common in those patients with post-operative PAL than in controls, and patients with PAL also had a significantly increased length of stay (14.2 vs. 7.1 days, $\mathrm{P}<0.001)$ (4). In addition to increased length of hospital stay, other authors have reported increased risk of pulmonary infection and empyema for post-lobectomy patients who develop PAL without an associated increase in mortality $(6,12,15)$. Not surprisingly, these complications also predictably result in increased health care costs associated with PAL (6).

Although little good data exists regarding morbidity and mortality of PAL resulting from spontaneous pneumothorax, it is very likely that PAL in this population also results in increased complications and costs related to hospital admission and prolonged inpatient stays. Data from Pierson and colleagues regarding PAL in mechanically ventilated patients did demonstrate significant mortality in those patients with PAL. Mortality in this cohort was $67 \%$, and in those patients who were not victims of trauma mortality was $92 \%$. Larger volumes of air leak per breath were also associated with increased observed mortality in this cohort (14). The generalizability of this prognostic data to a broader population, particularly in the current age of low tidal volume ventilation, is questionable. However, it seems likely that the presence of a PAL in mechanically ventilated patients would at the very least increase length of stay and health care costs as it has been shown to do in postsurgical patients.

\section{Management strategies}

PAL present a challenging management problem. No guidelines that are focused on PAL were found in our literature review. The 2001 American College of Chest Physicians consensus statement on spontaneous pneumothorax does briefly address the management of PAL after spontaneous pneumothorax. Based on expert consensus, they recommend thoracic surgical consultation if the air-leak persists beyond 4 days, and they recommend medical pleurodesis if the patient is not a surgical candidate (16). The most recent British Thoracic Society pleural disease guideline on spontaneous pneumothorax also briefly discusses PAL. Their recommendation is for surgical consultation if the air-leak persists beyond 48 hours. In patients who are medically inoperable they recommend chemical pleurodesis or chest tube with one-way flutter valve as alternatives (7). While these guidelines do recommend surgical treatment for PAL, they do not offer many other options for patients with a PAL who are not 
candidates for surgery and they do not address post-surgical air-leaks. Medical pleurodesis may not be ideal or effective for patients who have air-leaks so brisk that visceral and parietal pleural apposition is not achievable. Maintaining an intrapleural catheter with a one-way flutter valve may also allow for outpatient management in some patients, but the risk of pleural space infection is increased and some degree of social support is needed for optimal care of the chest tube $(17,18)$. Conservative management with chest tube placement and observation is often the initial choice and is usually effective (2). When this approach fails management strategies are generally divided into surgical and nonsurgical approaches, including bronchoscopic techniques. Overall goals of treatment are to maintain acceptable oxygenation and ventilation, to decrease or resolve the air leak allowing for full lung expansion if possible, to decrease length of stay, and to prevent recurrence of the air leak and subsequent pneumothorax.

\section{Conservative management}

Conservative management of a PAL generally consists of chest tube drainage and observation. There is not a current consensus on whether or not placing the chest tube to suction delays the time needed for the fistulous tract to heal. Some authors contend that water seal rather than active suction promotes healing of the alveolar-pleural fistula in pneumothorax by decreasing flow of air through the defect and thereby improving apposition of the lung tissue (19-21). Others believe that applying suction removes air from the pleural space at a rate greater than that of air leakage via the visceral pleural defect, promoting apposition between the visceral and parietal pleura thus enhancing healing $(7,21)$. Trials in the surgical literature that have evaluated suction vs water seal for post-operative air-leaks have yielded conflicting results, although it must also be noted that in these trials the air leaks were not necessarily persistent. Cerfolio et al. evaluated 33 patients with air leaks on the second post-operative day after lung resection. They were randomized to water seal or continuous suction $\left(-20 \mathrm{cmH}_{2} \mathrm{O}\right)$. The air leaks of the patients placed on water seal were more likely to resolve by post-operative day 3 than those on suction, although patients with very brisk leaks (33\%) did not resolve on water seal alone (22). Brunelli and colleagues randomized 145 patients with post-lobectomy air leaks on the first post-operative day to receive water seal or continuous suction $\left(-20 \mathrm{cmH}_{2} \mathrm{O}\right)$. They found no difference in duration of air leak or incidence of prolonged air-leak (23). Only one randomized trial evaluated the use of suction versus no suction after surgery for primary spontaneous pneumothorax. The investigators randomized 100 patients undergoing surgery for spontaneous pneumothorax to water seal or continuous suction $\left(-20 \mathrm{cmH}_{2} \mathrm{O}\right)$. They found that those patients placed on water seal rather than suction had chest tubes removed earlier, a shorter duration of hospital stay, and a lower rate of prolonged air leak (24).

If the air leak persists but it is not large enough to require suction to keep the lung expanded, then outpatient management with a one-way flutter valve can be effective. Drawbacks of this approach include discomfort with prolonged chest tube, increased risk of pleural infection, malfunction or malposition of the valve leading to reaccumulation of pneumothorax with tension, and patient dissatisfaction with fluid leaking from the drainage system $(17,18,25,26)$. Other elements of conservative management include management of pleural of pulmonary infection, treatment of the underlying disorder causing the PAL, and adequate nutritional support to promote healing (27).

Predicting when conservative management is likely to fail may be useful in that it allows the treating physician to intervene earlier to palliate the air-leak and reduce hospital length of stay and costs. Several studies of post-operative patients have evaluated risk factors for PAL after lobectomy or LVRS $(3,4,10,11)$. These are most useful in identifying those patients at high risk for PAL who may benefit from prophylactic intraoperative strategies to reduce that risk. They are not as helpful in deciding if a given leak is likely to become persistent once it has developed (28). More useful in this regard may be using newer chest drainage systems that allow for digital measurement of air-leak flow. Brunelli and colleagues demonstrated that measurements of air leak flow and intrapleural pressures using such a device 6 hours after lobectomy could aid in estimating the risk of PAL (29). Pilot studies of digital chest drainage systems in both surgical and non-surgical pneumothorax patients have also demonstrated their utility in helping clinicians decide when to remove chest tubes by quantifying the amount of airleak $(28,30)$. The ability of such digital drainage systems to not only measure the rate of air leak but monitor its change over time may allow physicians to predict which air leaks are likely to resolve without intervention and which ones are more likely to benefit most from early active management. Prospective controlled trials are still needed to validate this hypothesis.

In general, there are three factors that we always consider 
when assessing an air-leak: volume, trend, and duration. While an early large leak that is not trending down is unlikely to resolve with conservative management, a small leak that shows daily improvement will. Drainage systems with digital measurement of air leak flow may allow us to more accurately assess these factors.

\section{Surgical management of $P A L$}

Surgical management of PAL has long been the mainstay of therapy in those patients in whom air leaks do not resolve using conservative means. However, our aging population is slowly decreasing the number of patients who are fit for surgery. A number of surgical approaches have been described, varying somewhat with the underlying cause of the air leak. In post-surgical air leaks, drainage of any empyema with reinforcement of the stump or area of resection are typical (27). The reported rate of successful surgical treatment of postoperative PAL is between $80 \%$ and $95 \%(9,31-33)$. Of note, many patients are either not candidates for repeat surgery or prefer a less invasive technique. For air leaks after secondary spontaneous pneumothorax, surgical management includes resection of any blebs, bullae, or visible abnormalities of the visceral pleura as well as mechanical and/or chemical pleurodesis to achieve pleural symphysis $(1,7,34)$. Both video assisted thorascopic surgery (VATS) and open thoracotomy are effective. Recurrence rates for secondary spontaneous pneumothorax with PAL are slightly lower with thoracotomy than VATS, but the morbidity of thoracotomy is higher $(1,7)$. Mortality of surgical treatment of PAL is low, but morbidity is significant $(7,9,34)$. Again, some patients are not candidates for surgical management because they are medically inoperable, because they decline surgery, or because less morbid non-surgical techniques are attempted first.

\section{Non-surgical management of PAL}

\section{Medical pleurodesis}

Medical chemical pleurodesis is recommended by existing guidelines for spontaneous pneumothorax for recurrence prevention in those patients with PAL who are not candidates for surgery, although the evidence of its effectiveness is mixed $(7,16)$. The most commonly used sclerosing agents for this indication are tetracycline derivatives and talc (35). Animal studies initially suggested that tetracycline pleurodesis might be effective for treating pneumothorax with PAL (36). Subsequent studies in humans were less encouraging. In a small series of six patients Wang et al. demonstrated a failure rate of $83 \%$ for tetracycline pleurodesis in patients with spontaneous pneumothorax with PAL (37). The largest study to date was published by Light and colleagues in 1990 . They randomized 229 patients to receive either intrapleural tetracycline or usual care. Results showed that pleurodesis with tetracycline did reduce the recurrence rate of spontaneous pneumothorax overall. However, analysis of the subset of 39 patients who had PAL at the time of randomization showed no benefit of tetracycline pleurodesis in those patients with air leak (38). A subsequent study of tetracycline pleurodesis for spontaneous pneumothorax found similarly disappointing results in the subgroup of patients with PAL, with a pleurodesis failure rate of $40 \%$ (39). The use of talc for medical chemical pleurodesis in patients with PAL has not been well studied, although it was shown to be more effective than tetracycline for prevention of recurrence of spontaneous pneumothorax without air leak (40). The major adverse effect of pleurodesis with tetracycline or minocycline is severe chest pain (35). Although the pain seen with talc is less severe than that seen with tetracycline, empyema is occasionally seen with talc pleurodesis, as is acute respiratory distress syndrome (ARDS) (19). ARDS in talc pleurodesis is thought to be related to extrapleural dissemination of talc when preparations containing smaller size particles are used (41). This risk is much lower if graded talc with only larger size particles is utilized (42).

\section{Blood pleurodesis}

Blood pleurodesis, or "blood patch", is a technique in which the patient's own venous blood is instilled into the pleural space where it coagulates, sealing the site of the air leak (43). The volume of blood to be instilled varies in different reports, from $50 \mathrm{~mL}$ to $200 \mathrm{~mL}$ per instillation (5,43-45). The chest drainage tubing is then either clamped or more often elevated relative to the position of the patient and the pleural vacuum drain to allow air to escape while keeping the infused blood inside the pleural space $(43,44)$. Robinson initially reported successful treatment of PAL in 21 of 25 patients with spontaneous pneumothorax by using autologous blood pleurodesis as an adjunct to surgery (45). Dumire and colleagues reported successful use of blood pleurodesis in both a postoperative PAL and a PAL secondary to spontaneous pneumothorax (5). Other authors report rates of success ranging from $27 \%$ to $85 \%$ $(43,44,46)$. Interestingly, Cao and colleagues randomized 
44 patients with PAL from spontaneous pneumothorax to receive intrapleural instillation of $1 \mathrm{~mL} / \mathrm{kg}$ normal saline placebo or 3 different doses or volumes of autologous blood for pleurodesis. They found that at doses of 1 or $2 \mathrm{~mL} / \mathrm{kg}$, blood pleurodesis was effective at resolving PAL $82 \%$ of the time. This was significantly better than the $27 \%$ rate of success reported for a dose of $0.5 \mathrm{~mL} / \mathrm{kg}$ or $9 \%$ for saline placebo (43).

\section{Bronchoscopic management of PAL}

\section{Localizing the air leak}

Until recently the primary role of bronchoscopy in patients with PAL was to help localize the site of the air leak, with little if any impact on treatment beyond that (16). With the continued rapid development of more advanced therapeutic bronchoscopic techniques the role of bronchoscopy in the management of PAL has expanded dramatically. Nevertheless, the first step and probably the most crucial one remains the accurate localization of the air leak. This is generally the most tedious but important step in bronchoscopic treatment of PAL, no matter which therapeutic technique is utilized. It is frequently the case that more than one segment or even lobe are contributing to the air leak because of distal collateral ventilation within the same lobe, incomplete fissure or the presence of multiple areas of visceral pleural damage. For this reason, a patient and systematic approach to localize the leak is important. Careful review of the patient's history, procedure or operative report, and review of computed tomography (CT) imaging may help guide this process.

The most commonly used method for localization is selective balloon bronchial occlusion $(47,48)$. This procedure is preferably done under general anesthesia with an endotracheal tube to keep the system airtight. A large (size 8.5 or larger) endotracheal tube is recommended to prevent decrease of the air leak because of decreased ventilation around the bronchoscope within a smaller sized tube. Once anesthesia is induced the pleural vacuum drain or digital chest drain is positioned so that it can be observed by the bronchoscopy team during balloon occlusion. Then a balloon catheter is advanced through the working channel of the flexible bronchoscope and positioned initially in a proximal airway ipsilateral to the air leak. Most bronchoscopists begin with a lobar bronchus, though on the right side the starting point could be the right bronchus intermedius. Once the balloon is inflated and the selected bronchus is fully occluded, the chest drain is observed for $2-3$ minutes for evidence that the leak is decreasing. If the air leak lessens or stops with occlusion of the first bronchus, the balloon is deflated and then positioned in each more distal segment until the leak is fully localized. It should be the goal of the bronchoscopists to resolve the leak blocking the least amount of bronchial segments. If the leak does not change during the initial occlusion, a different lobar bronchus is chosen and the process is repeated until the leak is localized. Of note, the air leak may not change immediately after occlusion of the affected lobe because the air remaining in the unventilated portion of the lung gradually leaks out with each breath. It is important therefore to keep the balloon inflated long enough to give the leak a chance to decrease before moving on to the next area.

In some cases, the air leak becomes intermittent or ceases after anesthesia is induced for bronchoscopy, making localization using selective bronchial occlusion impossible. The reasons for this phenomena are not clear, but it may be due to the location of the chest tube (i.e., posterior), the supine position of the patient, development of atelectasis after induction of anesthesia, or decreased ventilation around the bronchoscope when using a small endotracheal tube. Vial and colleagues have developed an ingenious method to overcome this situation and they have named it "endobronchial oxygen insufflation" (49). This simple technique uses low flow oxygen insufflation to localize the site of air leak. Instead of blocking bronchi with a balloon to diminish the air leak, since there is no evident leak, they induce it by selectively insufflating oxygen in different bronchial segments. Oxygen tubing with flow set to between 2 and $4 \mathrm{~L} / \mathrm{min}$ is attached to the suction valve of the flexible bronchoscope. This enables insufflation of oxygen at low flow into the bronchial tree via the working channel of the instrument. The bronchoscope is then positioned in the airways of interest and oxygen is insufflated in short ( 2 second) bursts by depressing the button on the suction valve of the bronchoscope. The chest drain is observed during insufflation and the presence of bubbles or an increase in the rate of flow at that time confirms the site of the air leak (49). Another alternative method of localizing the site of the leak has been reported by van Zeller et al. They were able to successfully localize the leaking portion of lung by instilling methylene blue into the chest tube and observing in which bronchopulmonary segments it appeared, allowing them to successfully treat the PAL (50). 


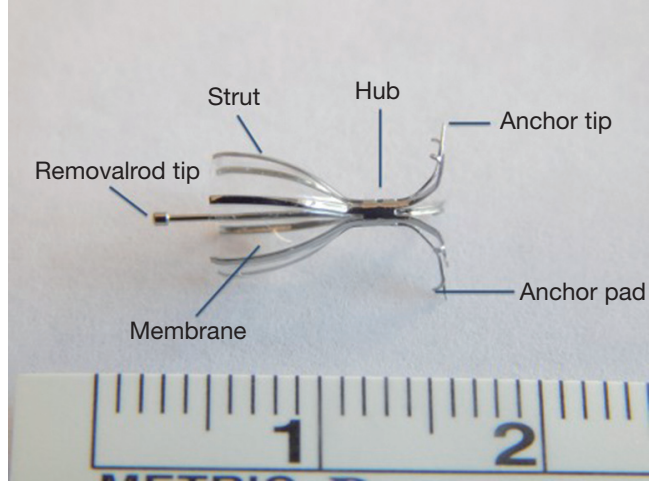

Figure 1 Intrabronchial valve.

Bronchoscopic sealants, sclerosants, and implants for PAL A number of compounds have been instilled bronchoscopically to attempt to close off the site of persistent air leaks. Most have been reported as small case series or case reports. Among the sealants reported are fibrin or fibrin glue (51-53), cyanoacrylate glue $(54,55)$, oxidized cellulose (56), albuminglutaraldehyde glue [2004], and hydrogel (57). Our review found no comparative studies, but reported complications are infrequent. Sclerosants have also been used to treat PAL by causing inflammation and fibrosis at the site of the tissue defect. Reported sclerosants include ethanolamine (58), ethanol (59), and tetracycline (60). Endobronchial implants have also been used to palliate air leaks. The endobronchial Watanabe spigot is a silicone implantable bronchial filler which was developed to treat PAL. In the original trial of 60 patients with PAL 23 had a complete cessation of air leak after placement of the spigot, and 22 more had a reduction in the air leak (61). The device is somewhat cumbersome to use and has not been widely adopted. Endobronchial placement of vascular embolization coils, with and without the addition of sealant, has also been used to treat PAL with limited success $(62,63)$. Overall results for sealants, sclerosants, and implants have been mixed, and larger comparative studies are needed to truly determine their optimal use.

\section{Bronchoscopically placed one-way valves}

More recently one way valves that can be placed bronchoscopically to occlude airways leading to sites of PAL have been developed. They allow air and secretions to escape but prevent air from entering the portion of the lung aerated by the occluded airway. This leads to partial volume loss of the blocked portion of lung and decreased air flow through the alveolar-pleural fistula. Such valves were initially developed to treat patients with emphysema and hyperinflation, but they have been adopted for use in treatment of PAL as well with significant success $(47,48)$. Two valve systems have been best studied for lung volume reduction and PAL. The Zephyr ${ }^{\circledR}$ endobronchial valve (EBV, Pulmonx Inc. Neuchatel, Switzerland) has a nitinol framework supporting a silicone "duck bill". Several sizes are available for different size airways. The EBV is approved for use in many countries outside the United States. The intrabronchial valve (IBV, Spiration Inc. Redmond, Washington, USA) consists of a nitinol framework covered with a polymer membrane shaped like an umbrella. It is held in place by 5 anchors to reduce the risk of migration (Figure 1). The IBV system is approved for use in many countries outside the Unites States and received approval by the Unites States Food and Drug Administration in 2008 under a Humanitarian Device Exemption for treatment of PAL after lung surgery. The current recommendation is that the valves be removed after 6 weeks since the alveolarpleural fistula should have healed by then. The IBV is available in 4 sizes to accommodate bronchial diameters between 5 and $9 \mathrm{~mm}$.

The effective use of the EBV for treating PAL was initially described in a series of case reports, each of which described a patient with PAL after surgery (64-67). Subsequent reports describe using EBV successfully for PAL resulting from mechanical ventilation, infections, thoracentesis, and secondary spontaneous pneumothorax (68-70). The largest series to date describing the use of EBV for PAL was published by Travaline and colleagues. Endobronchial valves were used to treat 40 patients in 17 centers for PAL. Etiologies of PAL included spontaneous pneumothorax, post-surgical, other iatrogenic causes, and trauma. A significant improvement in the air leak was seen in $92 \%$ of patients treated, with $19 / 40$ (47.5\%) having complete resolution of the air leak. Adverse events occurred in $6 / 40(15 \%)$ of patients, including valve expectoration, infection, and malposition. No deaths were attributable to valve procedures (47). Valve migration has also been reported by other authors, but its true incidence in patients who received EBV for air leaks is unknown (71).

Intrabronchial valves (IBVs) have also demonstrated effectiveness for treating PAL as well. Gillespie and colleagues published the first multicenter case series in 2011, with seven patients undergoing 8 successful IBV placement procedures for complex and prolonged air leaks. All patients had improvement in their air leak after IBV placement. All five patients in whom subsequent removal 
of the valves was attempted had this done successfully. No complications were noted (48). Other subsequent series have confirmed this success. El-Sameed et al. reported four cases of PAL treated with IBV successfully without complication (72). Cornwell and collaborators reviewed a series of 15 patients with PAL at a large Veterans Affairs hospital, 12 of whom had large leaks and were strictly suction-dependent (patients developed large pneumothorax when placed on water seal). After treatment with a mean of 3.87 IBVs ten patients (67\%) had complete resolution of their air leak within 2 days. Of the 12 patients who were suction-dependent prior to IBV placement 11 were able to be placed on water seal immediately after the valve procedure. No major complications were seen, and only two patients had minor complications. In 11 cases subsequent valve removal was attempted, and all IBV removals were completed successfully (73). It is important to emphasize that even in situations where a complete resolution of the leak is not achieved, a partial response that allows to liberate patients from wall suction can be key in reducing length of stay (since patients can then be discharged with a flutter valve, for example). The largest study to date of IBV for air leaks reviewed 75 patients undergoing IBV placement at 8 centers. Off-label indications for valve placement were present in $71 \%$ of patients. The mean time from air leak identification to bronchoscopic treatment was 9 days. Complete follow-up data was available for only 59 of the 75 patients who received valves. Of those 59 patients $33(55 \%)$ had complete resolution of the air leak within 1 day of valve implantation. Complications were reported in two patients, and ten patients were eventually discharged home with continued chest drainage (74). IBVs have also been used to treat PAL in patients who are critically ill or being mechanically ventilated with sufficient improvement in the air leak and respiratory status that extubation and eventual ICU discharge were possible (75). No migration or expectoration of IBV has been reported. A randomized trial (NCT02382614) comparing placement of IBV to standard therapy for PAL is ongoing.

Combining bronchoscopic valve placement with digital measurement of the degree of air leak shows great promise for streamlining the management process. The ability to quantify the amount of air leak may allow rapid identification of responders to valve placement after the procedure, facilitating earlier chest tube removal and reducing hospital length of stay in these patients $(76,77)$. In addition, during bronchoscopy, these digital flow monitoring systems can help us more accurately recognize partial response after selective balloon occlusion that can be missed when only looking at the degree of "bubbling".

\section{Placing of IBV valves}

Bronchoscopic valve placement is typically done in the operating room or bronchoscopy suite. We will describe the technique for intrabronchial valve placement here since that device is approved for use in the United States as well as other countries. The procedure for placing the endobronchial valve is similar. General anesthesia and moderate sedation have both been used, though we favor the former with an endotracheal tube to allow for an airtight system. If general anesthesia is used a size 8.5 or larger endotracheal tube are recommended to prevent decrease of the air leak because of decreased ventilation around the bronchoscope within a smaller sized tube (78). Air leak isolation is completed as described above. Once the leak is isolated the airways to be blocked must be sized in order to choose an optimally sized valve to occlude it with good fit. The IBV system comes with a balloon catheter and airway sizing calibration kit for this purpose. Once the balloon is calibrated it is advanced through the working channel of the bronchoscope into the airway to be occluded. The balloon is then inflated until it is gently touching the bronchial wall in its entire circumference. While it should be able to be moved back and forth when inflated a small amount of resistance is felt when the balloon is properly inflated (Figure 2). Overinflating the balloon to the point of dilation or distention of the airway should be avoided as this will result in selecting an oversized valve, which will "wrinkle" and not block air flow as effectively as one that is optimally sized. Once properly inflated the degree of inflation is recorded on the reference chart that is part of the calibration kit and the proper size valve is selected. The properly sized valve is loaded into the deployment catheter and the catheter is inspected to ensure good position and no kinking. Then the catheter is introduced via the working channel of the bronchoscope. The tip of the removal rod, which is the proximal end of the valve itself, should be just touching the tip of the stabilization wire. If there is a significant space between them, it should be removed in order to improve the accuracy of placement and prevent kinking of the catheter. This is done by removing the safety clip and gently pressing the proximal catheter handle until the gap is closed (78). This last step- “closing the gap"-is no further needed with the latest multiple valve deployment system. Subsequently, the bronchoscope and catheter are advanced into the target 


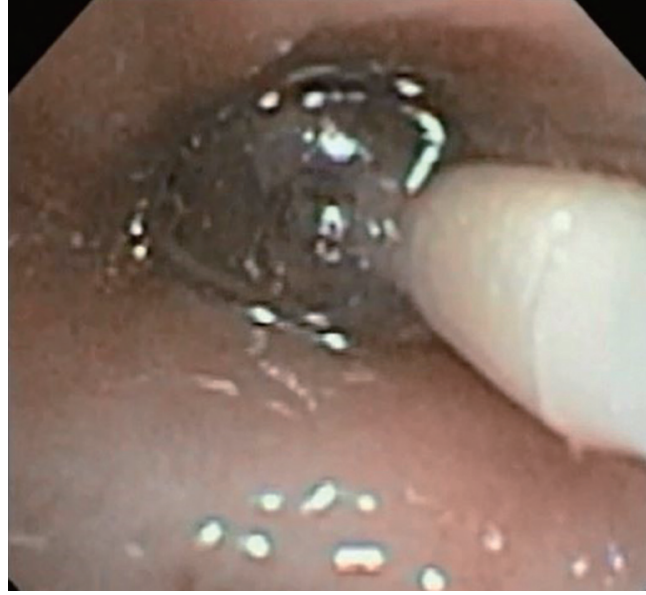

Figure 2 Sizing balloon inflated in the target airway.

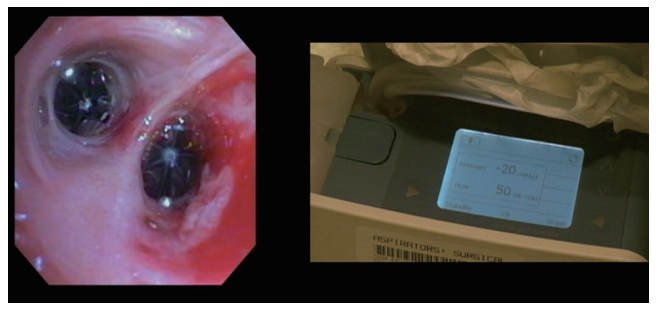

Figure 3 Intrabronchial valves in the left image and digital chest drain measuring $50 \mathrm{~mL} / \mathrm{min}$ flow in the right image.

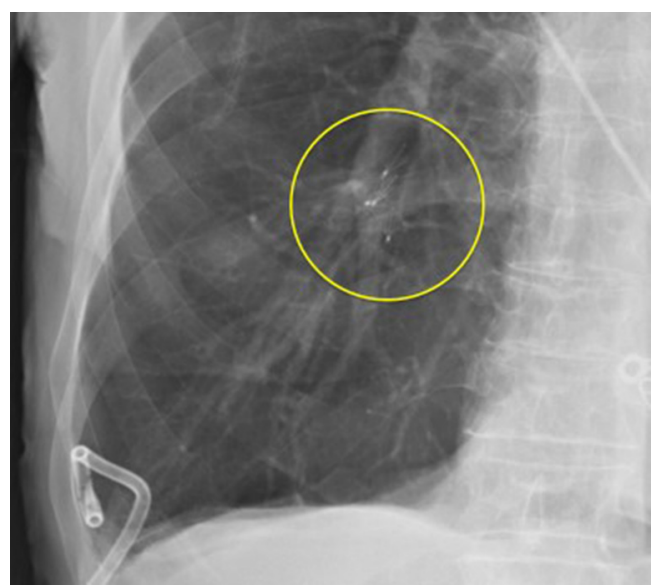

Figure 4 Chest X-ray showing re-expansion of lung after placement of 3 intrabronchial valves in the right lower lobe. airway. The yellow dotted line on the deployment catheter indicates the proximal end of the polymer "umbrella". This one should be aligned with the desired location, and then the valve is deployed by pressing the catheter handle gently in a continuous movement over about $2 \mathrm{~s}$ timed to coincide with full inspiration. The catheter is then removed from the bronchoscope. The valve is observed for several respiratory cycles to ensure good positioning, and the air leak is monitored as well to determine if the desired decrease has been achieved (Figure 3). Post procedure chest X-rays are typically obtained to determine if the lung has expanded or remained expanded and to establish the original position of valves (Figure 4).

Patients who undergo successful IBV placement should be reassessed for potential valve removal about 6 weeks after placement. Removal is a straightforward process but best accomplished through an endotracheal tube under general anesthesia to protect the vocal cords during removal (78). The valve removal rod is grasped with forceps and gently retracted until it comes free from the bronchial wall and until it is flushed against the distal end of the scope. The valve, forceps, and bronchoscope are then removed "en bloc" from the airway. Care must be taken not to pull the valve into the working channel of the bronchoscope during removal, as this may damage the instrument.

\section{Conclusions}

PAL is an important problem in patients who undergo lung surgery and in those with significant parenchymal lung disease suffering from a pneumothorax. It is associated with significant morbidity and increased health care costs. Conservative treatment with chest drainage and observation is effective most of the time. When it fails, surgical management should be considered. Unfortunately, the morbidity of surgery is significant and many patients with severe lung disease are poor operative candidates. For this specific group of patients and for those who do not desire surgery, nonsurgical treatment should be offered. Pleurodesis with medicines or blood can be used, but controlled studies are lacking. Numerous bronchoscopic techniques have also been described in small case series with variable results. These include various sealants, sclerosants, and implanted devices. The most promising bronchoscopic treatment currently is the placement of oneway valves within the airways leading to the area of the lung from where the PAL is originating. Early reports have demonstrated success as well as a low rate of complications, 
even in poor surgical candidates. A randomized trial to further clarify the role of bronchoscopic valve placement in the management of PAL is underway.

\section{Acknowledgements}

None.

\section{Footnote}

Conflicts of Interest: DR Lazarus has received research grants from Spiration. RF Casal has received research grants from PneumRx, Spiration, and Siemens, and is a paid-consultant for Olympus.

\section{References}

1. Noppen M, De Keukeleire T. Pneumothorax. Respiration 2008;76:121-7.

2. Chee CB, Abisheganaden J, Yeo JK, et al. Persistent airleak in spontaneous pneumothorax--clinical course and outcome. Respir Med 1998;92:757-61.

3. DeCamp MM, Blackstone EH, Naunheim KS, et al. Patient and surgical factors influencing air leak after lung volume reduction surgery: lessons learned from the National Emphysema Treatment Trial. Ann Thorac Surg 2006;82:197-206; discussion 206-7.

4. Liberman M, Muzikansky A, Wright CD, et al. Incidence and risk factors of persistent air leak after major pulmonary resection and use of chemical pleurodesis. Ann Thorac Surg 2010;89:891-7; discussion 7-8.

5. Dumire R, Crabbe MM, Mappin FG, et al. Autologous "blood patch" pleurodesis for persistent pulmonary air leak. Chest 1992;101:64-6.

6. Varela G, Jimenez MF, Novoa N, et al. Estimating hospital costs attributable to prolonged air leak in pulmonary lobectomy. Eur J Cardiothorac Surg 2005;27:329-33.

7. MacDuff A, Arnold A, Harvey J, et al. Management of spontaneous pneumothorax: British Thoracic Society Pleural Disease Guideline 2010. Thorax 2010;65:ii18-31.

8. Mathur R, Cullen J, Kinnear WJ, et al. Time course of resolution of persistent air leak in spontaneous pneumothorax. Respir Med 1995;89:129-32.

9. Lois $M$, Noppen $M$. Bronchopleural fistulas: an overview of the problem with special focus on endoscopic management. Chest 2005;128:3955-65.

10. Stolz AJ, Schutzner J, Lischke R, et al. Predictors of prolonged air leak following pulmonary lobectomy. Eur J
Cardiothorac Surg 2005;27:334-6.

11. Brunelli A, Monteverde M, Borri A, et al. Predictors of prolonged air leak after pulmonary lobectomy. Ann Thorac Surg 2004;77:1205-10; discussion 10.

12. Abolhoda A, Liu D, Brooks A, et al. Prolonged air leak following radical upper lobectomy: an analysis of incidence and possible risk factors. Chest 1998;113:1507-10.

13. Rivera C, Bernard A, Falcoz PE, et al. Characterization and prediction of prolonged air leak after pulmonary resection: a nationwide study setting up the index of prolonged air leak. Ann Thorac Surg. 2011;92:1062-8; discussion 8 .

14. Pierson DJ, Horton CA, Bates PW. Persistent bronchopleural air leak during mechanical ventilation. A review of 39 cases. Chest 1986;90:321-3.

15. Brunelli A, Xiume F, Al Refai M, et al. Air leaks after lobectomy increase the risk of empyema but not of cardiopulmonary complications: a case-matched analysis. Chest 2006;130:1150-6.

16. Baumann MH, Strange C, Heffner JE, et al. Management of spontaneous pneumothorax: an American College of Chest Physicians Delphi consensus statement. Chest 2001;119:590-602.

17. Van Hengel P, Van de Bergh JH. Heimlich valve treatment and outpatient management of bilateral metastatic pneumothorax. Chest 1994;105:1586-7.

18. Gogakos A, Barbetakis N, Lazaridis G, et al. Heimlich valve and pneumothorax. Ann Transl Med 2015;3:54.

19. Stradling P, Poole G. Conservative management of spontaneous pneumothorax. Thorax 1966;21:145-9.

20. Bintcliffe OJ, Hallifax RJ, Edey A, et al. Spontaneous pneumothorax: time to rethink management? Lancet Respir Med 2015;3:578-88.

21. Pompili C, Salati M, Brunelli A. Chest tube management after surgery for pneumothorax. Thorac Surg Clin 2017;27:25-8.

22. Cerfolio RJ, Bass C, Katholi CR. Prospective randomized trial compares suction versus water seal for air leaks. Ann Thorac Surg 2001;71:1613-7.

23. Brunelli A, Monteverde M, Borri A, et al. Comparison of water seal and suction after pulmonary lobectomy: a prospective, randomized trial. Ann Thorac Surg 2004;77:1932-7; discussion 7.

24. Ayed AK. Suction versus water seal after thoracoscopy for primary spontaneous pneumothorax: prospective randomized study. Ann Thorac Surg 2003;75:1593-6.

25. Crocker HL, Ruffin RE. Patient-induced complications of a Heimlich flutter valve. Chest 1998;113:838-9. 
26. Campisi P, Voitk AJ. Outpatient treatment of spontaneous pneumothorax in a community hospital using a Heimlich flutter valve: a case series. J Emerg Med 1997;15:115-9.

27. El-Sameed YA. Role of Bronchoscopy in Management of Bronchopleural Fistula. In: Mehta AC, Jain P, editors. Interventional Bronchoscopy: A Clinical Guide. New York: Springer Science+Business Media, 2013;211-25.

28. Mueller MR, Marzluf BA. The anticipation and management of air leaks and residual spaces post lung resection. J Thorac Dis 2014;6:271-84.

29. Brunelli A, Cassivi SD, Salati M, et al. Digital measurements of air leak flow and intrapleural pressures in the immediate postoperative period predict risk of prolonged air leak after pulmonary lobectomy. Eur J Cardiothorac Surg 2011;39:584-8.

30. Tunnicliffe G, Draper A. A pilot study of a digital drainage system in pneumothorax. BMJ Open Respir Res 2014;1:e000033.

31. Stamatis G, Freitag L, Wencker M, et al. Omentopexy and muscle transposition: two alternative methods in the treatment of pleural empyema and mediastinitis. Thorac Cardiovasc Surg 1994;42:225-32.

32. Hollaus PH, Huber M, Lax F, et al. Closure of bronchopleural fistula after pneumonectomy with a pedicled intercostal muscle flap. Eur J Cardiothorac Surg 1999; 16:181-6.

33. Sabanathan S, Richardson J. Management of postpneumonectomy bronchopleural fistulae. A review. J Cardiovasc Surg (Torino) 1994;35:449-57.

34. Sahn SA, Heffner JE. Spontaneous pneumothorax. N Engl J Med 2000;342:868-74.

35. How CH, Hsu HH, Chen JS. Chemical pleurodesis for spontaneous pneumothorax. J Formos Med Assoc 2013;112:749-55.

36. Macoviak JA, Stephenson LW, Ochs R, et al. Tetracycline pleurodesis during active pulmonary-pleural air leak for prevention of recurrent pneumothorax. Chest 1982;81:78-81.

37. Wang Y'T, Ng KY, Poh SC. Intrapleural tetracycline for spontaneous pneumothorax with persistent air leak. Singapore Med J 1988;29:72-3.

38. Light RW, O'Hara VS, Moritz TE, et al. Intrapleural tetracycline for the prevention of recurrent spontaneous pneumothorax. Results of a department of veterans affairs cooperative study. JAMA 1990;264:2224-30.

39. Alfageme I, Moreno L, Huertas C, et al. Spontaneous pneumothorax. Long-term results with tetracycline pleurodesis. Chest 1994;106:347-50.
40. Almind M, Lange P, Viskum K. Spontaneous pneumothorax: comparison of simple drainage, talc pleurodesis, and tetracycline pleurodesis. Thorax 1989;44:627-30.

41. Ferrer J, Montes JF, Villarino MA, et al. Influence of particle size on extrapleural talc dissemination after talc slurry pleurodesis. Chest 2002;122:1018-27.

42. Janssen JP, Collier G, Astoul P, et al. Safety of pleurodesis with talc poudrage in malignant pleural effusion: a prospective cohort study. Lancet 2007;369:1535-9.

43. Cao G, Kang J, Wang F, et al. Intrapleural instillation of autologous blood for persistent air leak in spontaneous pneumothorax in patients with advanced chronic obstructive pulmonary disease. Ann Thorac Surg 2012;93:1652-7.

44. Oliveira FH, Cataneo DC, Ruiz RL Jr, et al. Persistent pleuropulmonary air leak treated with autologous blood: results from a university hospital and review of literature. Respiration 2010;79:302-6.

45. Robinson CL. Autologous blood for pleurodesis in recurrent and chronic spontaneous pneumothorax. Can J Surg 1987;30:428-9.

46. Karangelis D, Tagarakis GI, Daskalopoulos M, et al. Intrapleural instillation of autologous blood for persistent air leak in spontaneous pneumothorax- is it as effective as it is safe? J Cardiothorac Surg 2010;5:61.

47. Travaline JM, McKenna RJ Jr, De Giacomo T, et al. Treatment of persistent pulmonary air leaks using endobronchial valves. Chest 2009;136:355-60.

48. Gillespie CT, Sterman DH, Cerfolio RJ, et al. Endobronchial valve treatment for prolonged air leaks of the lung: a case series. Ann Thorac Surg 2011;91:270-3.

49. Vial MR, Lan C, Cornwell L, et al. Endobronchial oxygen insufflation: a novel technique for localization of occult bronchopleural fistulas. Ann Am Thorac Soc 2013;10:157-9.

50. van Zeller M, Bastos P, Fernandes G, et al. Clinical challenges of persistent pulmonary air-leaks--case report. Rev Port Pneumol 2014;20:162-6.

51. York EL, Lewall DB, Hirji M, et al. Endoscopic diagnosis and treatment of postoperative bronchopleural fistula. Chest 1990;97:1390-2.

52. Hollaus PH, Lax F, Janakiev D, et al. Endoscopic treatment of postoperative bronchopleural fistula: experience with 45 cases. Ann Thorac Surg 1998;66:923-7.

53. Finch CK, Pittman AL. Use of fibrin glue to treat a persistent pneumothorax with bronchopleural fistula. Am J Health Syst Pharm 2008;65:322-4. 
54. Roksvaag H, Skalleberg L, Nordberg C, et al. Endoscopic closure of bronchial fistula. Thorax 1983;38:696-7.

55. Wood RE, Lacey SR, Azizkhan RG. Endoscopic management of large, postresection bronchopleural fistulae with methacrylate adhesive (Super Glue). J Pediatr Surg 1992;27:201-2.

56. Sprung J, Krasna MJ, Yun A, et al. Treatment of a bronchopleural fistula with a Fogarty catheter and oxidized regenerated cellulose (surgicel). Chest 1994;105:1879-81.

57. Mehta HJ, Malhotra P, Begnaud A, et al. Treatment of alveolar-pleural fistula with endobronchial application of synthetic hydrogel. Chest 2015;147:695-9.

58. Lim AL, Kim CH, Hwang YI, et al. Bronchoscopic ethanolamine injection therapy in patients with persistent air leak from chest tube drainage. Tuberc Respir Dis (Seoul) 2012;72:441-7.

59. Takaoka K, Inoue S, Ohira S. Central bronchopleural fistulas closed by bronchoscopic injection of absolute ethanol. Chest 2002;122:374-8.

60. Martin WR, Siefkin AD, Allen R. Closure of a bronchopleural fistula with bronchoscopic instillation of tetracycline. Chest 1991;99:1040-2.

61. Watanabe Y, Matsuo K, Tamaoke A, et al. Bronchial occlusion with endobronchial watanabe spigot. J Bronchology Interv Pulmonol 2003;10:264-7.

62. Watanabe S, Watanabe T, Urayama H. Endobronchial occlusion method of bronchopleural fistula with metallic coils and glue. Thorac Cardiovasc Surg 2003;51:106-8.

63. Salmon CJ, Ponn RB, Westcott JL. Endobronchial vascular occlusion coils for control of a large parenchymal bronchopleural fistula. Chest 1990;98:233-4.

64. Snell GI, Holsworth L, Fowler S, et al. Occlusion of a broncho-cutaneous fistula with endobronchial one-way valves. Ann Thorac Surg 2005;80:1930-2.

65. Feller-Kopman D, Bechara R, Garland R, et al. Use of a removable endobronchial valve for the treatment of bronchopleural fistula. Chest 2006;130:273-5.

66. Mitchell KM, Boley TM, Hazelrigg SR. Endobronchial valves for treatment of bronchopleural fistula. Ann Thorac Surg 2006;81:1129-31.

67. Ferguson JS, Sprenger K, Van Natta T. Closure of a

Cite this article as: Lazarus DR, Casal RF. Persistent air leaks: a review with an emphasis on bronchoscopic management. J Thorac Dis 2017;9(11):4660-4670. doi: 10.21037/ jtd.2017.10.122 bronchopleural fistula using bronchoscopic placement of an endobronchial valve designed for the treatment of emphysema. Chest 2006;129:479-81.

68. Toma TP, Kon OM, Oldfield W, et al. Reduction of persistent air leak with endoscopic valve implants. Thorax 2007;62:830-33.

69. Anile M, Venuta F, De Giacomo T, et al. Treatment of persistent air leakage with endobronchial one-way valves. J Thorac Cardiovasc Surg 2006;132:711-2.

70. Santini M, Fiorelli A, Vicidomini G, et al. Latrogenic air leak successfully treated by bronchoscopic placement of unidirectional endobronchial valves. Ann Thorac Surg 2010;89:2007-10.

71. Jenkins M, Vaughan P, Place D, et al. Endobronchial valve migration. Eur J Cardiothorac Surg 2011;40:1258-60.

72. El-Sameed Y, Waness A, Al Shamsi I, et al. Endobronchial valves in the management of broncho-pleural and alveolopleural fistulae. Lung 2012;190:347-51.

73. Cornwell LD, Panchal R, Bakaeen FG, et al. Bronchoscopic management of prolonged air leaks with endobronchial valves in a veteran population. JAMA Surg 2017;152:207-9.

74. Gilbert CR, Casal RF, Lee HJ, et al. Use of oneway intrabronchial valves in air leak management after tube thoracostomy drainage. Ann Thorac Surg 2016;101:1891-6.

75. Mahajan AK, Verhoef P, Patel SB, et al. Intrabronchial valves: a case series describing a minimally invasive approach to bronchopleural fistulas in medical intensive care unit patients. J Bronchology Interv Pulmonol 2012;19:137-41.

76. Firlinger I, Stubenberger E, Muller MR, et al. Endoscopic one-way valve implantation in patients with prolonged air leak and the use of digital air leak monitoring. Ann Thorac Surg 2013;95:1243-9.

77. Dooms CA, Decaluwe H, Yserbyt J, et al. Bronchial valve treatment for pulmonary air leak after anatomical lung resection for cancer. Eur Respir J 2014;43:1142-8.

78. Mahajan AK, Doeing DC, Hogarth DK. Isolation of persistent air leaks and placement of intrabronchial valves. J Thorac Cardiovasc Surg 2013;145:626-30. 